\title{
Consideration of risk and safety in stratification metamodeling system
}

\author{
Valdemar Vitlinskyi ${ }^{1}$, and Vyacheslav Glushchevsky ${ }^{2, *}$ \\ ${ }^{1}$ Kyiv National Economics University named after Vadym Hetman, Economical and Mathematical Modeling Department, \\ 03057, Kyiv, Ukraine \\ ${ }^{2}$ Zaporizhzhia National University, Economics and Informational Technologies Department, 69006, Zaporizhzhia, Ukraine
}

\begin{abstract}
The development of the concept and tools of stratification metamodeling (SMM) is proposed, which is a new object-oriented methodological approach to the synthesis of a complex model of the economic system (enterprise), in particular, in order to distinguish the set of variants of the combination of heterogeneous object-components of its various strata into a single hierarchical structure. It is emphasized that it is necessary to consider conceptual provisions and tools for evaluation and management of such systemic characteristics as safety and risk in the system of the SMM in order to increase the sustainability of the economic system under consideration.
\end{abstract}

\section{Introduction}

Socioeconomic systems (SES), first of all anthropogenic microeconomic systems, objectively inherent risks that are permanently modified in the dynamic environment, conflict with each other, creating new, unknown till present time risks. By substantially reducing one of the risk groups, we can thus increase the risks associated with another group. The multidimensionality of these risks permanently creates threats to the economic security of the SES.

In our opinion, economic security is an integrated system characteristic, which depends on the stability, the permissible level of risk, the controllability of parameters in order to ensure the development and protection of vital economic interests of the individual and society, economic stability of the subjects of economic relations and the economy as a whole [1].

Adding of the principle of uncertainty and the resulting risk in the axiomatics of economic systems functioning makes it more appropriate to consider complex economic systems as self-evident, and also points to the need to consider, evaluate and manage the degree of risk in the system of economic security.

We emphasize that risk is one of the key features of the essence of being, a systemic characteristic in the field of economics. As we have emphasized, the risk has a dialectical objective-subjective structure, as discussed in detail, in particular in [2]. One can give such a definition of the risk in the economy.

Risk is an economic category that characterizes the degree of threats posed by possible losses, failures, deviations from goals, and lowering the level of security. At the same time, risk reflects the peculiarities of the perceived interest of the subjects concerned in economic relations of uncertainty, conflict, threats connected with the current state and the predicted course of events that can lead both to the positive (desirable) and to the negative (undesirable) economic result, from taking into account direct and inverse relationships.

Risks are manifested as threats to the stable (planned) functioning of the SES (hereinafter referred to as enterprises). The current state and prospects of economic development of Ukraine and its industrial segment are characterized by a number of existing problems, in particular such as: radical transformation of global chains of value creation and complication of information structure of modern enterprises; asynchronous management of cross-enterprise processes, digitalization and intellectualization of their control systems; the complexity of tasks solved by managers of all levels due to the ambiguity of situations due to the increase in the number of significant factors and the significant growth of the problem in a holistic and comprehensive analysis of these situations, taking into account the revealed hidden underlying relationships and factors; combining and mixing various technologies of the physical, digital and biological worlds on the basis of a single information platform, etc.

Decision-making process is entrusted to a person (the head of a certain rank), but the activity of people is objectively limited due to the diversity and super-high structural-logical-functional complexity of the investigated phenomena and processes of the subject area on the one hand, and on the other - on the one hand, and on the other, partial absence of a priori information about the probable movement of the economic system and the natural limitations of the human brain in analyzing the tree of events in their interconnection, complementarity, and / or vice versa, the mutual exclusion etc. Therefore, it is logical to involve in the processes of decisions substantiation of modern information technologies (IT) to

\footnotetext{
* Corresponding author: gluschevsky@ukr.net
} 
strengthen the work of the human brain and create on this basis a human-machine decision support systems, which requires the transformation of existing business models of operational type into digital models of activities that support full automation, robotizing, computerization of all functional areas of the enterprise, work with large data sets and are the basis for creation of supercomplicated and super-powerful control systems based on corporate IT.

The rapid development of IT and their application to the automation of managerial processes generated an important direction of intellectualization of processes supporting management decisions - automation of counteraction to threats to the enterprise and, as a consequence, elimination or risk reduction of occurrence of unwanted events (threats) by the way of developing of information-analytical and intelligent systems of automated decision support with elements of artificial intelligence and their introduction into the practice of traditional management of enterprises [3-6].

Under these conditions, for enterprises and economic systems of different levels, the problem of aggregation of large volumes of information - the results of monitoring of a variety of aspects of the activity of the environment is being updated. The latter significantly alter the input parameters of management models, may have a destabilizing effect, and, therefore, cause an increase in the uncertainty of the situation and the resulting risk and, as a consequence, the instability of the economic system.

Enterprises that are interested in increasing the stability of their own business and the predictability of development trajectories, evaluate the level of awareness of the tendencies and regularities of processes in the external environment as a measure of conceptual advantage. It is precisely this - the targeted securityprotection meaning becomes an economic risk in the information (digital) economy, and the corresponding change in the managerial and model paradigm is grounded historically and methodologically [2, 7-10].

Mathematical modeling as a method of researching of processes and phenomena has become the intellectual core of information technology for the analysis, foundation and adoption of rational and effective solutions in the field of economics and entrepreneurship. But now there is an urgent need for a substantial rethinking of the methodological provisions and tools used in the theory and practice of economic and mathematical modeling.

Rational and most expedient is the combination in the modeled system of adaptive enterprise management of the principles and elements of system, situational, process, marketing and other approaches to management in order to form qualitatively new structures and management mechanisms; it should be based on the quality management system, comply with international and Ukrainian standards, the observance of which guarantees the quality of products and services, as well as the high efficiency of the management system [11].

In recent decades, proactive management acquires in the modeling of economic systems, which is understood as purposeful activity, which involves the activation of systemic transformations that lead to the formation of potentially promising states of the economic system in order to maintain its parameters of life, functioning and development. In particular, the work of [12] formulates the principles which were laid down in the basis of a practical approach. This paper also emphasizes the need to consider the uncertainty and generated risk in the system of proactive management.

It is also important that the predictions of key indicators and parameters can be developed more precisely, based on artificial intelligence tools, by implementing alternative scenarios of events and the development of the external environment and the researched system, which are necessary for making wellbalanced decisions. It is also necessary to take into account new types of uncertainty, conflict and the resulting risk, the security and viability of the analyzed economic systems [1].

It should be noted that in our time the conceptual provisions concerning metamodeling have developed considerably, and the stratification tools are developing as the basis for engineering modeling of control systems. At the same time, it is important to synthesize the methodology of metamodeling and stratification tools based on the system-synergistic approach [11, 13-21].

Scientists are intensively and fruitfully working on the development of methodological foundations and the corresponding mathematical tools for modeling adaptive control systems based on the stratification metamodeling methodology for system synthesis and coordination of asynchronous models of dynamically interacting subsystems of the analyzed economic systems in order to increase the validity and efficiency of managerial decisions. In our opinion, the perspective direction in the simulation of economic systems and processes is the synthesis of artificial systems of intelligence enhancement and the methodology and tools of stratification metamodeling. Therefore, it is necessary to develop intensively the scientific research in this direction [11].

\section{Result and discussion}

\subsection{Glossary}

We suggest using the following concepts (author's development) [11]:

Stratification - an analysis of the enterprise from different points of view (modeling aspects) and the corresponding perspective multi-dimensional decomposition with the purpose of developing and synchronizing different segments of knowledge (stratum) with the simultaneous logical integrity of all of these knowledge.

The technology of metamodeling - a system of forms, methods, tools, methodological techniques and procedures of hierarchical modeling, with the application of which the structural and functional structure of the enterprise is considered from a certain point of view considering the objectives of the study.

Stratification metamodeling is a new (proposed by the authors) object-oriented approach to the synthesis of a complex enterprise model in order to select a plurality of variants of unification of heterogeneous object- 
components of its various stratums into a single hierarchical structure - the stratification metamodel of the enterprise, on which basis a system multivariate analysis and dynamic evaluation of the combined effect of different objects of each stratum on the variability of adaptive management of enterprise cross-processes is done.

Metamodel of stratum is a complex model of an enterprise that allocates certain levels of abstraction (meta-levels) in the description of enterprise objects and a plurality of their models located at different meta-levels, and ensures their logical and algorithmic consistency at meta-levels and between them within this stratum.

Stratification metamodel of the enterprise is a spatial structural and functional complex model that unifies, organizes and synchronizes information interconnections between heterogeneous models of object-components (local model complexes) of all strata in the scale and context of the enterprise as a whole.

\subsection{Methodology}

We propose reengineering of the enterprise management system based on a unified corporate information system, taking into account the priority of decentralization of management, preferential modeling of business processes of the enterprise as a network structure on the basis of the stratification metamodeling methodology (SMM). Let us highlight the following main stages of the practical application of SMM-methodology.

Stage 1. Development, introduction, improvement of the enterprise quality management system based on the international standards of the ISO 9000: 2005 series, IDT, ISO 9001: 2008, IDT (with additions) taking into account the specifics of the classes of enterprises grouped by types of economic activity [22].

Stage 2. Model reengineering of the functional structure of the enterprise (model of the network of business processes): system decomposition of the enterprise into separate parts (organizational units, functional departments, business processes, etc.); reengineering of business processes taking into account the results of modeling of multidimensional structural and functional relationships between the allocated components [23].

Stage 3. Mathematical support of corporate information systems for information support of managerial processes is based on integrated models of enterprise activity, application of which provides model compatibility, balance and functional interoperability of heterogeneous object-components of a single corporate information model of enterprise management system. Consideration, quantification of risks and safety, as well as models of management of these system characteristics, considering the dialectical objective and subjective risk structure [24].

Stage 4. Synthesis of the ERM-model (or ERMsolution - Enterprise Reference Modeler) of the enterprise management system based on the principles of stratification applied to the complex model of the enterprise:
- the processes of functioning of the enterprise are described in various aspects and with different levels of abstraction (the isolation of strata);

- METAMODEL complex model is represented by a set of structural, functional and informative models;

- the synthesis of these models into a single complex, the establishment of the coordination links between model components, the introduction of a uniform format of indicators, parameters, data for information exchange in the scale of the entire model complex is carried out using the methodology and tools of stratification metamodeling, in which systems are systematically integrated methods of structural and functional and object-oriented modeling, graphic description of the structures of simulated enterprise subsystems, metadata-based technologies grounded on MDD models (Model-Driven Development) and other tools for integrating models (nested, hierarchical structures) [4, 25].

Stage 5. Designing a single corporate information ERM-model of an enterprise-wide management system based on BPM - a concept (Business Performance Management) that implements an innovative approach to management - automated support for a complete cycle of business efficiency management aimed at optimizing the implementation of strategic development of an enterprise by the way of integrating cyclic analytical processes supported by relevant information technologies [26].

\subsection{Modeling}

Model support for selected stages of the practical application of SMM-methodology is provided by the $S M M$ toolkit - various mathematical, software and hardware tools, case studies of relevant normative and legal documentation are developed.

Stage 1. Development of ISO 9000 series standards for a specific enterprise based on TQM (Total Quality Management) [22, 26].

Stage 2. The modeling of the company as a complex dynamic system in the form of the stratification metamodel METAMODEL involves the creation of integrated two of its complex models $M O D E L^{O S}$ and $M O D E L^{B P}$, functional and logical connections of structural elements which are coordinated among themselves on the basis of the toolbox SMM [11].

2.1. The first aspect of enterprise modeling (first stratum). The object model MODEL ${ }^{O S}$ of the general virtual organizational management structure (OMS) is proposed, which is constructed using the tools of graph theory and organizational modeling based on its real analog as an artificial mixed-type OMS taking into account various conceptual models (linear, functional, matrix, design, network OMS models and their combinations) and presented in the form of an oriented weighted graph:

$$
M O D E L^{O S}=\left\langle V^{O S} ; E^{O S} ; W^{O S}\right\rangle,
$$

where $V^{O S}=\left\{O S_{i}\right\}=\left\{O S_{i \alpha_{i}}\right\}, E^{O S}=\{\Gamma ; \Omega\}$ - is the set of vertices and arcs respectively of the $M O D E L^{O S}$ graph, $i \in I, \alpha_{i} \in \mathrm{A}_{i}$ - identifiers; $O S_{i}, O S_{i_{1}}, O S_{i_{2}}$ - structural divisions of the enterprise ( $i, i_{1}, i_{2}-$ their identifiers); 


$$
\left\{\begin{array}{l}
\Gamma: V^{O S} \times V^{O S} \rightarrow\{-1 ; 0 ; 1\} \\
\Omega: V^{O S} \times V^{O S} \rightarrow\{0 ; 1\},
\end{array}\right.
$$

where $\Gamma=\left\{\gamma_{i_{1} i_{2}}\right\}_{i_{1} ; i_{2} \in \mathrm{I}}$ - is the set of direct control pulses, which is represented by a modified adjacency matrix: $\quad \forall i_{1}, i_{2} \in \mathrm{I}, i_{1} \neq i_{2}: \gamma_{i_{1} i_{2}}: O S_{i_{1}} \times O S_{i_{2}} \rightarrow$ $\{-1 ; 0 ; 1\} ; \Omega=\left\{\omega_{i_{1} i_{2}}\right\}_{i_{1} ; i_{2} \in \mathrm{I}}-$ is the set of inverse regulating responses, which is represented by the adjacency matrix: $\forall i_{1}, i_{2} \in \mathrm{I}, i_{1} \neq i_{2}: \omega_{i_{1} i_{2}}: O S_{i_{2}} \times$ $O S_{i_{1}} \rightarrow\{0 ; 1\} ; W^{O S}=\{\Psi ; \Phi\}-$ is a system of measured functions that are given on the sets $V^{O S}$ and $E^{O S}$ of the $M O D E L^{O S}$ graph, respectively.

2.2. Adapting the enterprise to change by creating a "target design teams" to solve actual problem situations (countering threats to economic security) involves decomposing using the technology of metamodeling of the general model $M O D E L^{O S}$ into partial models in the form of oriented weighted subgraphs $M O D E L^{O S}$ :

$$
\begin{gathered}
M O D E L^{O S}=\left\{M L_{\pi}^{(1)}\right\}_{\pi \in \Pi} \\
\left\{\begin{array}{l}
M L_{\pi}^{(1)}=\left\langle V_{\pi}^{O S} ; E_{\pi}^{O S} ; W_{\pi}^{O S}\right\rangle: \\
V_{\pi}^{O S}=\left\{O S_{i}\right\}_{i \in I_{\pi}} ; V_{\pi}^{O S}: C M_{\pi} \times V^{O S} \rightarrow\{0 ; 1\} \\
E_{\pi}^{O S}=\left\{\Gamma_{\pi} ; \Omega_{\pi}\right\} ; W_{\pi}^{O S}=\left\{\Psi_{\pi} ; \Phi_{\pi}\right\}
\end{array}\right.
\end{gathered}
$$

where $M L_{\pi}^{(1)}$ - partial models of the virtual OMS of the enterprise, which are artificially constructed to solve the actual problem situation $\pi ; V_{\pi}^{O S}, E_{\pi}^{O S}, W_{\pi}^{O S}$ - are the sets of vertices corresponding to the arcs of the graph $M L_{\pi}^{(1)}$ and the system of weighted functions given on the sets $V_{\pi}^{O S}$ and $E_{\pi}^{O S}, \pi \in \Pi, I_{\pi} \subseteq I, \Gamma_{\pi} \subseteq \Gamma, \Omega_{\pi} \subseteq \Omega, \Psi_{\pi} \subseteq \Psi$, $\Phi_{\pi} \subseteq \Phi ; C M_{\pi}$ - is a target conceptual model that is constructed to solve the actual problem situation $\pi \in \Pi$.

2.3. The second aspect of the enterprise modeling (second stratum). Integrated modeling of the business processes (BP) network of the enterprise was carried out using the metamodeling technology in the form of a directed graph $M O D E L^{B P}$ :

$$
M O D E L^{B P}=\left\langle V^{B P} ; E^{B P}\right\rangle,
$$

where $V^{B P}=\left\{B P_{n}\right\}=\left\{F S_{j_{n}}^{n}\right\}, E^{B P}$ - the set of vertices and arcs of the graph $M O D E L^{B P}$ respectively: vertices (heterogeneous objects) - models of individual business processes $\left\{M L_{n}^{(2)}\right\}$; arcs - coupling between pairs $B P_{n_{1}}$ and $B P_{n_{2}} ; n \in N, j_{n} \in J_{n}$ - identifiers.

2.4. Model reengineering of business processes for their continuous improvement. The set of objects of model $M O D E L^{B P}$ is formed by models $M L_{n}^{(2)}$ of individual business processes of the enterprise, which is built on the basis of international standards of quality of series ISO 9000 in the form of oriented weighted graphs:

$$
M L_{n}^{(2)}=\left\langle V_{n}^{B P} ; E_{n}^{B P} ; \widetilde{W}_{n}^{B P}\right\rangle, n \in N
$$

$$
\begin{aligned}
& \left\{\begin{array}{l}
V_{n}^{B P}=\left\{F S_{j}^{n}\right\}_{j \in J_{n}} \\
E_{n}^{B P}=\left\{F S J_{n}\right\}_{n \in N}=\left\{\left(F S_{j_{1}}^{n} ; F S_{j_{2}}^{n}\right)\right\}_{n \in N, j_{1} \neq j_{2}, j_{1}, j_{2} \in J_{n}} \\
\widetilde{W}_{n}^{B P}=\left\langle D E M^{2} ; D E M^{4} ; B R E S ; W\right\rangle_{n \in N}
\end{array}\right. \\
& {\left[\begin{array}{l}
F S J_{n}: V_{n}^{B P} \times V_{n}^{B P} \rightarrow\{0 ; 1\} \\
D E M_{n}^{2}: B P_{n} \times R S_{r} \rightarrow\{0 ; 1\} \\
D E M_{n}^{4}: B P_{n} \times P R_{p} \rightarrow\{0 ; 1\} \\
B R E S_{n}: B P_{n} \times R S_{r} \rightarrow \mathbb{Z}^{+}
\end{array}\right.}
\end{aligned}
$$

where $V_{n}^{B P}, E_{n}^{B P}$ - are the sets of vertices and arcs respectively of the graph $M L_{n}^{(2)} ; F S_{j}^{n}, F S_{j_{1}}^{n}, F S_{j_{2}}^{n}-$ functional blocks of the $\mathrm{n}$ business process model $\left(j, j_{1}, j_{2}\right.$ - their identifiers within the business process “ $n$ "); $\widetilde{W}_{n}^{B P}$ - is the system of weighted functions (objects) given on the sets $V_{n}^{B P}$ and $E_{n}^{B P}$ of the graph $M L_{n}^{(2)}, n \in N$, in particular: $D E M_{n}^{2}=\left\{d_{n r}^{2}\right\}-$ is a function of consumption of resources from the set $R S_{r}, r \in R$, on the elements of the $n$th business process $B P_{n} ; D E M_{n}^{4}=\left\{d_{n p}^{4}\right\}$ - output function of the product of the set $P R_{p}, p \in P$, for the $n$ business process $B P_{n} ; B R E S_{n}=\left\{b_{n r}\right\}$ - the function of providing the $n$th business process $B P_{n}$ the volume of $r$-type resources from the set $R S_{r}, r \in R ; W_{n}$ - the set of administrative tasks of the enterprise (object) that are solved on the functional elements of the business process $B P_{n} ; \mathbb{Z}^{+}-$is the set of integer positive numbers.

2.5. The formalization of "joints" between the pairs of business processes in the model structure MODEL ${ }^{B P}$ is carried out using the models in the form of dual-fraction oriented graphs of a special structure:

$$
\begin{gathered}
G_{n_{1} n_{2}}=\left\langle V_{n_{1} n_{2}} ; E_{n_{1} n_{2}} ; W_{n_{1} n_{2}}\right\rangle \\
\left\{\begin{array}{l}
V_{n_{1} n_{2}}=V_{n_{1}} \cup V_{n_{2}}, V_{n_{1}}=\left\{F S_{j_{n_{1}}}^{n_{1}}\right\}, V_{n_{2}}=\left\{F S_{j_{n_{2}}}^{n_{2}}\right\} \\
\left.E_{n_{1} n_{2}}: V_{n_{1}} \times V_{n_{2}} \rightarrow\{0 ; 1\}, E_{n_{1} n_{2}}=\left\{\left(F S_{j_{n_{1}}}^{n_{1}} ; F S_{j_{n_{2}}}^{n_{2}}\right)\right\}\right\},
\end{array}\right.
\end{gathered}
$$

where $V_{n_{1} n_{2}}, E_{n_{1} n_{2}}$ - are the plural of the graph $G_{n_{1} n_{2}}-$ respectively, the vertices (functional elements $F S_{j_{n_{1}}}^{n_{1}}$ and $F S_{j_{n_{2}}}^{n_{2}}$, which are the "joints" of business processes $B P_{n_{1}}$ and $B P_{n_{2}}$ respectively) and arcs that connect them; $W_{n_{1} n_{2}}$ - is a system of weighted functions (objects) given on the sets $V_{n_{1} n_{2}}$ and $E_{n_{1} n_{2}}$ of the graph $G_{n_{1} n_{2}}, n_{1}, n_{2} \in N$, $n_{1} \neq n_{2}, j_{n_{1}} \in J_{n_{1}}, j_{n_{2}} \in J_{n_{2}}$.

Step 3. To construct a comprehensive enterprise model, we suggest using a combination of the most wellknown and recognized in the world of architectural methodologies: the Zakhman model, the TOGAF (The Open Group Architectural Framework), the FEA (Federal Enterprise Architecture) methodology, the Gartner methodology, the EAP method (Enterprise Architecture Planning, as well as methods of structural analysis and design of business processes (IDEF, ARIS, their modifications and applied notations, MS Visio, etc.) $[4,6$, 27-32].

Stage 4. The reengineering of business processes of the enterprise is carried out on the basis of the model of the $M O D E L^{M S}$ of the spatial interaction of the organizational and functional structures of the enterprise by the way of integration of the object elements of their models $M O D E L^{O S}$ and $M O D E L^{B P}$ respectively (formulas 
(1) - (9)) with the use of SMM tools. The complex ERM model of the enterprise management system $M O D E L^{M S}$ is presented in the form of the oriented weighted graph with the formulas (10) - (12):

$$
\begin{aligned}
& M O D E L^{M S}=\left\langle V^{M S} ; E^{M S} ; \widetilde{W}^{M S}\right\rangle \\
& {\left[\begin{array}{l}
V^{M S}=V^{O S} \cup V^{B P} \\
E^{M S}=V^{O S} \times V^{B P} \rightarrow\{0 ; 1\} \\
\widetilde{W}^{M S}:\left\langle P^{1} ; P^{2} ; \widetilde{U} ; W\right\rangle
\end{array}\right.} \\
& \left\{\begin{array}{l}
P^{1}: V^{O S} \times F R \rightarrow\{0 ; 1\} \\
P^{2}: V^{B P} \times F R \rightarrow\{0 ; 1\} \\
\widetilde{U}: V^{O S} \times V^{B P} \times F R \rightarrow\{0 ; 1\} \\
W: \widetilde{U} \times R E S \times P R O D \rightarrow \bar{W}
\end{array}\right\}
\end{aligned}
$$

where:

$V^{M S}, V^{O S}, V^{B P}, E^{M S}=\left\{e_{i \alpha_{i} n j_{n}}\right\}=\left\{\left(O S_{i \alpha_{i}} ; F S_{j_{n}}^{n}\right)\right\}, \widetilde{W}^{M S}$ - is the set of vertices of $M O D E L^{M S}, M O D E L^{O S}$, $M O D E L^{B P}$, arcs of the $M O D E L^{M S}$ graph, and the system of objects (functions, weights, matrices described above), which are given on its sets $V^{M S}$ and $E^{M S}$, respectively, in particular: $P^{1}=\left\{\rho_{i \alpha_{i} s h_{s}}^{1}\right\}, \quad P^{2}=\left\{\rho_{n j_{n} s h_{s}}^{2}\right\} \quad-$ matrix identifiers of the "bindings" of the functional works $r_{s h_{s}}$ from the set $F R, s \in S, h_{s} \in \mathrm{H}_{s}$, to elements $O S_{i \alpha_{i}} \in V^{O S}$ and $F S_{j_{n}}^{n} \in V^{B P}$ in accordance; $\widetilde{U}=\left\{\tilde{u}_{i \alpha_{i} n j_{n}}\right\}-$ is the matrix-identifier of the direct management guidance pulses by the unit $O S_{i \alpha_{i}}$ on the functional block $F S_{j_{n}}^{n} ; W$, $\bar{W}-$ are the sets of management tasks $w_{n \lambda_{n}}$, which are solved by the units $O S_{i \alpha_{i}}$ on the functional elements $F S_{j_{n}}^{n}$ business processes of the enterprise using the resource set of RES for the production of the product the PROD set and the information descriptions $\bar{w}_{n \lambda_{n}}$ of their content statements: $W=\left\{w_{n \lambda_{n}}\right\}, \bar{W}=\left\{\bar{w}_{n \lambda_{n}}\right\}, \operatorname{RES}=\left\{R S_{r}\right\}$, $P R O D=\left\{P R_{p}\right\}, n \in N, \lambda_{n} \in \Lambda_{n}, r \in R, p \in P$.

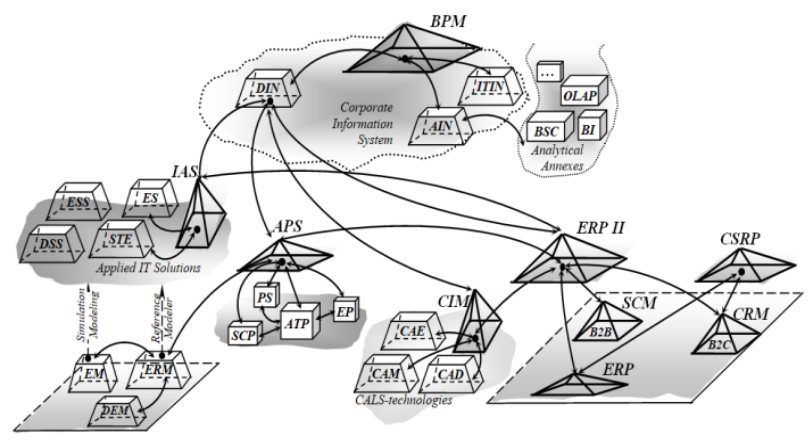

Fig. 1. Architecture of a single corporate information ERMmodel of enterprise management system based on BPMconcept.

Stage 5. Models of modern corporate information systems are developed on the basis of model stratification of the enterprise on a modular basis and contain a set of metamodels that are programmed implemented with the help of multifunctional information management technologies with a set of business applications (architectural modules) at the level of databases and knowledge for certain subject areas, which are adapted to the specifics and conditions of the operation of a particular enterprise. These methodological principles of modeling are the basis for the creation of the architecture of a single corporate information ERM-model enterprise management system based on the BPM-concept (Figure 1), which is endowed with referential properties and can be adapted and implemented at other enterprises that are related according to industrial and / or sectoral sign.

\subsection{Architecture of ERM-model}

The architecture of a single corporate information ERMmodel of an enterprise management system, which we offer within the framework of the SMM methodology, allows the inclusion, if necessary, to the basic BPM platform of separate specialized analytical techniques presented by separate IT-modules, in particular, such (Figure 1) [33-36].

BPM (Business Performance Management):

functionality of the module - automated support of the full cycle of management of the efficiency of activity at all levels of the enterprise by way of unification of owners, managers, personnel and external contractors within the general integrated management environment based on a single corporate information model of the enterprise;

modeling tools - methods: functional-cost (ABCCosting), scenario, situational and plan-fact analysis; methodology of the BSC (Balanced Scorecard); BI applications (Business Intelligence: data warehouses and displays, OLAP technologies, intelligent data analysis, etc.); AIN (Analytic Infrastructure) and DIN (Data Infrastructure) integration technologies for functional and informational collaboration of BPM-based applications from external sources (BPM-compliant with APS / CRM / SCM solutions, ERP / ERP II class systems), IAS set, CALS-technologies, etc.); ITIN-technology (ITinfrastructure: servers, data storage hardware, computing networks, operating systems, etc.); B2G (Business-toGovernment) and G2B (Government-to-Business) application-based software solutions, such as eprocurement systems, electronic tenders, etc.

ERPII (Enterprise Resource and Relationship Processing):

functionality of the module - integrated management of an enterprise of a certain type of economic activity (for sectoral / industrial segments) by way of automating cross-processes through their optimization, IT support and the introduction of automated CRM (Customer Relationship Management) and supply chains (SCMSupply Chain Management) based on Internet technologies;

modeling tools - methods and models of logistics (SCM-module), Internet-based technologies on the basis of $\mathrm{B} 2 \mathrm{~B}$ and $\mathrm{B} 2 \mathrm{C}$ platforms (Business-to-Business and Business-to-Consumer - application software solutions such as CRM components for the implementation of interactive interaction respectively, "enterprise-executorenterprise-customer" and "enterprise-client"), tools of the basic ERP-system, applied APS-system, control systems by databases and OLAP-technologies, etc.

CSRP (Customer Synchronized Resource Planning): 
functionality of the module - synchronization of business processes of the enterprise with the needs and expectations of consumers of its products by the way of business process reengineering and virtualization of its units and services;

modeling tools - Internet-based technologies B2Cplatforms, tools of the basic ERP system, applied APSsystems, control systems by databases and OLAP technologies, etc.

ERP (Enterprise Resource Planning):

functionality of the module - effective planning and management of all resources of the enterprise to provide an organizational strategy for the integration of production and operations management of labor resources, financial management and asset management;

modeling tools - methods, models, algorithms of the theory of production planning, statistical and economic analysis, the theory of schedules, group support decisionmaking, investment analysis, management accounting, financial and personnel management, etc.

IAS (Information and Analytical System):

module functionality is a human-computer system whose analytical modules together form a multifunctional integrated information system, with which the support for decision-making is supported;

modeling tools - traditional optimization methods: MathCAD, MATLAB; statistical data processing: STE (Statistica Enterprise), SPSS (Statistical Package for the Social Sciences); ES (Expert System), DSS (Decision Support System), ESS (Executive Support Systems), etc.

\section{CIM (Computer Integrated Manufacturing):}

functionality of the module - the integrator of separate computer systems and CALS-technologies into a single system for the automation of the entire production process from designing products to their manufacturing;

modeling tools - tools of the basic ERP system, applied CALS-technologies integrated with ERP system: CAD (Computer-aided design), CAE (Computer-aided engineering), CAM (Computer-aided manufacturing).

APS (Advanced Planning and Scheduling):

functionality of the module - adaptive management of the enterprise's production cycle for the management of production chains based on the application of economical mathematical methods and models;

component modules (standards):

ATP (Available To-Promise) - comprehensive assessment of the ability to execute the scheduled portfolio of orders in scheduled terms;

EP (Enterprise Planning) - optimization of planning processes: capacities, operational, material needs; PS (Production Scheduling) - volume scheduling; SCP (Supply Chain Planning) - planning a cumulative production process based on the "production chain" modeling;

EM - application (Enterprise Modeler) - scenario modeling for the development and quantification of the effectiveness of enterprise plans at all levels;

modeling tools - methods and models of mathematical programming, operations research, mathematical statistics, risk analysis, optimal management, decision making, simulation modeling, structural modeling (IDEF, ARIS methodology, etc.), heuristic methods, multicriterion models, object oriented technologies (UML; CBD; DFM, etc.), business process reengineering methods: DEM (Dynamic Enterprise Modeler), ERMsolutions (Enterprise Reference Modeler), other methods and models of economic cybernetics.

The BPM platform provides the implementation of simple analytical functions that are implemented with built-in OLAP tools (generalization / detailing, benchmarking, etc.), and the only corporate information ERM-model of the enterprise management system built on the basis of the methodology and with the use of stratification metamodeling tools, enables to solve the actual problem of asymmetry of model information in the system of management of economic safety of the enterprise and has the following advantages:

- universality (the possibility to describe the structure of the $E R M$-model, the characteristics and functionality of the classes of models using the METAMODEL stratification metamodel, and the standardization and unification of the models created for various problem areas - the system evaluation of individual risk groups); - modularity (structurization of the METAMODEL stratification metamodel as a system of interconnected and conditionally separated local model complexes while maintaining its integrity - identifying "hidden" links between the components of the detected threat and multidimensional assessment of the integration risk of the threat of the onset of a particular problem situation); - the system of relations within the hierarchy (at each level of the hierarchy of the ERM-model, its individual IT modules may be assigned their own rules for representing their objects and interrelationships between them leveling the threat of the "exit" of a particular problem situation beyond the functional of the ERM-model due to the application of its construction of the principles of multilayer hierarchy);

- adaptability (the ability of the ERM-model to flexible modification and extensions of model and hardware complexes at any hierarchical level without a fundamental modification of its structural basis - model synthesis (model simulation) of a chain of problem situations or a certain set of them);

- interoperability (the ability of the ERM-model to integrate adequately and non-conflict with other external entities in relation to it, formalized objects, excluding any restrictions on mutual access to jointly activated information and computing resources, in particular models, sets of models, model complexes, metamodels of data and knowledge, etc. - the basis for automated control of the chain of task models through "access points" due to the intellectualization of the decision-making model in the structure of stratification metamodel of METAMODEL).

\section{Conclusion}

Thus, the mastery of the principles and mechanisms embodied in the BPM concept enables top management to determine and measure the effectiveness of the enterprise by improving the reflection of the assessment of its own business, on the basis of which to implement program- 
targeted efficiency management on its basis which is grounded on strategic priorities of the development. The main hidden reserves for obtaining a positive effect from the introduction of BPM-systems built on the basis of the proposed methodology of SMM, is saving various types of costs (reducing costs of IT processing transactions in the system optimization of flow processes throughout the production chain; eliminating the risks of making incorrect or false calculations; obtaining a synergistic effect by coordinating processes, optimizing functions, targeted improvement in indicative indicators, etc.) and a long-term competitor and benefits for the next 15-20 years due to the flexibility of management in responding to market changes and as a result ensure high performance and profitability of investment attractiveness.

The methodology of $S M M$ is the basis for accumulation and reuse of knowledge when creating templates of ERM-models, which are reference for the classes of enterprises, due to the flexible combination of conceptual, mathematical and information descriptions of the models of enterprises with the use of stratification metamodeling tools.

We would like to emphasize that the inclusion of conceptual provisions and tools of safety and risk in the framework of the SMM is a prerequisite for ensuring efficient, proactive management of the SES in the realities of the information (digital) economy.

This study was supported by the Ukrainian Ministry of Education and Science, Project No. 0116U002596, "Development of Methodology and Toolkit of Modeling Risks in the System of Economic Security".

\section{References}

1. Katunina O.S., Vitlinskyy V.V.: Otsiniuvannia rivnia ekonomichnoi bezpeky na pidgrunti modeliuvannia znan (Evaluation of the level of economic security on the basis of knowledge modeling). Modeliuvannia ta informatsiini systemy v ekonomitsi. 93, 74-90 (2017)

2. Vitlinskyy V.V.: Metodolohichni zasady modeliuvannia ryzyku $\mathrm{v}$ systemi ekonomichnoi bezpeky (Methodological basis of risk modeling in the economic security system). Modeliuvannia ta informatsiini systemy v ekonomitsi. 94, 5-28 (2017)

3. Portilla, A., Vazquez, J., Harreis, H., Pancaldi, L., Rowshankish, K., Samandari, H., Staples, M. (ed.): The future of risk management in the digital era. https://www.mckinsey.com/ /media/McKinsey/Busi ness $\% 20$ Functions/Risk/Our\%20Insights/The\%20fut ure $\% 20$ of $\% 20$ risk $\% 20$ management $\% 20$ in $\% 20$ the $\% 2$ 0digital $\% 20$ era/Future-of-risk-management-in-thedigital-era-IIF-and-McKinsey.ashx (2017). Accessed 29 March 2019

4. Kudrjavcev D.V., Arzumanjan M.U.: Arhitektura predprijatija: perehod ot proektirovanija ITinfrastruktury $\mathrm{k}$ transformacii biznesa (Enterprise Architecture: Transition From IT-Infrastructure Design to Business Transformation). Russian Management Journal. 15(2), 193-224 (2017). doi:10.21638/11701/spbu18.2017.204
5. Kravchenko V.H.: Proektuvannia avtomatyzovanykh informatsiinykh system. KNEU, Kyiv (2008)

6. Koehler T., Alter S.: Using enterprise architecture to attain full benefits from corporate big data while refurbishing legacy work systems. CEUR Workshop Proceedings. 1753, 1-11 (2016)

7. Vahlakova, V.V.: Ekonomichna bezpekolohiia: stanovlennia nauky (The Formation of the Science of Economic Security). Probl. of Ec. 1, 290-296 (2017)

8. Heiets, V.M. (ed.): Modeliuvannia ekonomichnoi bezpeky: derzhava, rehion, pidpryiemstvo (Simulation of economic security: state, region, enterprise). INZhEK, Kharkiv (2006)

9. Illyashenko, O.V.: Pobudova systemy ekonomichnoi bezpeky pidpryiemstva: pryntsypovi polozhennia (Building of a system of enterprise economic security: principals). Efektyvna ekonomika. 11 (2015)

10. Europe 2020: A European strategy for smart, sustainable and inclusive growth. http://ec.europa.eu/eu2020/pdf/COMPLET\%20EN\% 20BARROSO $\% 20 \% 20 \% 20007 \% 20$ \%20Europe \%202020\%20-\%20EN\%20version.pdf (2010). Accessed 29 March 2019

11. Glushchevsky, V.V.: Prykladni aspekty zastosuvannia tekhnolohii stratyfikatsiinoho metamodeliuvannia $\mathrm{v}$ systemi upravlinnia komertsiinym bankom (Applied aspects of application of stratificational metamodeling technology in commercial bank management systems). In : Cherniak, O.I., Zakharchenko, P.V. (eds). Applied Aspects of Forecasting Development of the UE, pp. 234-250. Melitopol (2018)

12. Chornous, H.O.: Proaktyvne upravlinnia sotsialnoekonomichnymy systemamy na osnovi intelektualnoho analizu danykh: metodolohiia i modeli (Proactive management of socio-economic systems on the basis of intellectual data analysis: methodology and models). Kiev University, Kyiv (2014)

13. Van Gigch, J.P.: System Design Modeling and Metamodeling. Plenum Press, New York (1991)

14. Kangassalo, H.: Approaches to the Active Conceptual Modeling of Learning. In: Chen, P., Wong, L. (eds.) Active Conceptual Modeling of Learning: Next Generation Learning-Base System Development, pp. 168-193 (2007). doi:10.1007/978-3-540-775034_14

15. Olive, A.: Conceptual Modeling of Information Systems. Springer, Berlin (2007)

16. Mesarovic, M.D.: Multilevel concept for systems engineering. Proc. Sys. Eng. Conf., Chicago (1965)

17. Mesarovic, M.D., Macko, D., Takahara, Y.: Structuring of multilevel systems. Proc. IFAC Symp. Multivariable Systems, Dusseldorf (1968)

18. Nechaev, V.V.: Vvedenie $\quad \mathrm{V}$ teoriju metamodelirovanija sistem (Introduction to the theory of system metamodeling). Moscow (1997)

19. Ljadova, L.: Metamodelirovanie i mnogourovnevye metadannye kak osnova tehnologi sozdanija 
adaptiruemyh informacionnyh sistem (Meta-modeling and multi-level metadata as a basis for technologists of creating adaptable information systems). Int. J. "Information Technologies \& Knowledge": Int. B. Series "Information Science \& Computing". 4, 125132. http://scigems.math.bas.bg/jspui/bitstream/10525/1093/1/IBS04-p20.pdf (2008). Accessed 29 March 2019

20. Lychkina, N.N., Morozova, Ju.A.: Stratifikacija kak osnova inzhenerii tehnologij komp'juternoj podderzhki prinjatija gosudarstvennyh reshenij $\mathrm{V}$ pensionnoj sfere (Stratification as the basis of computer technology engineering support for making state decisions in the pension sphere). Business Informatics. 2(20), 20-28 (2012)

21. Atkinson, K., Kjune, T.: Fundament metamodelirovanija (The foundation of metamodeling).

https://www.osp.ru/os/2003/12/183688/

(2003). Accessed 29 March 2019

22. ISO 9001:2000 Quality management systems Requirements. http://www.iso.org/iso/catalogue_detail?csnumber=2 1823 (2000). Accessed 29 March 2019

23. Hammer, M., Champy, J.: Reengineering the Corporation: A Manifesto for Business Revolution. Harper Collins, New York (1993)

24. Novikov, D.A.: Kompleksnye modeli sistemnoj optimizacii proizvodstvenno-jekonomicheskoj dejatel'nosti predprijatija (Complex models of system optimization of production and economic activity of the enterprise). Large system management, 65, 118152 (2017)

25. Macko, D.: General systems theory approach to multilevel systems. Systems Res. Center Rep. SRC 106-A-67-44 (1967)

26. ISO/IEC 24744:2014 Software Engineering Metamodel for Development Methodologies. https://webstore.iec.ch/preview/info isoiec 24744\%7 Bed2.0\%7Den.pdf (2014). Accessed 29 March 2019

27. Seshns, R.: Sravnenie chetyreh vedushhih metodologij postroenija arhitektury predprijatija (Comparison of the four leading methodologies for building enterprise architecture). https://docs.microsoft.com/ru-ru/previousversions/dotnet/articles/ee914379(v=msdn.10) (2007). Accessed 29 March 2019

28. ARIS Express - besplatnaja programma dlja modelirovanija biznes-processov i orgstruktury (ARIS Express is a free program for modeling business processes and organizational structures). http://bpmsoft.org/aris-express (2014). Accessed 29 March 2019

29. IDEF Family of Methods: A Structured Approach to Enterprise Modeling \& Analysis. http://www.idef.com/. Accessed 29 September 2018

30. Zachman, J.A.: John Zachman's Concise Definition of the Zachman Framework. Zachman International, Inc. https://www.zachman.com/about-the-zachmanframework (2008). Accessed 29 March 2019

31. Lapalme, J., Gerber, A., Van der Merwe, A., Zachman, J., De Vries, M., Hinkelmann, K.: Exploring the future of enterprise architecture: A Zachman perspective. Comp. in Ind. 79, 103-113 (2016)

32. Machulko, O.I.: Sravnenie metodologij postroenija arhitektur korporativnyh informacionnyh sistem (Comparison of methodologies for building architectures of corporate information systems). $\mathrm{J}$. Modern trends in the development of science and technology. 3(3), 88-89 (2017)

33. ISO 15704:2000 Industrial automation systems Requirements for enterprise-reference architectures and methodologies. International organization for standardization.

https://www.iso.org/standard/28777.html

(2000). Accessed 29 March 2019

34. Avtomatizacija upravlenija kompanijami: BPM (Automation of company management: Business Performance Management). http:/www.insapov.ru/business-performancemanagement.html (2006). Accessed 29 March 2019

35. Business Performance Management Industry Framework Document. Final Version 5.0. BPM Standards

Group. http://www.bpmpartners.com/documents/BPMIndust ryFramework-V5.pdf (2005). Accessed 29 Sep 2018

36. Standarty upravlenija MRP, MRP II, ERP, CSRP. CRM-sistemy (Management Standards MRP, MRP II, ERP, CSRP. CRM-systems). http://kursak.net/standarty-upravleniya-mrp-mrp-iierp-csrp-crm-sistemy/ Accessed 29 March 2019 